\section{A mobile field-work data collection system for the wireless era of health surveillance}

\author{
Marianne Forsell,' Petteri Sjögren, ${ }^{2}$ \\ Matthew Renard,' Olle Johansson ${ }^{3}$ \\ 'Oral Care AB, Stockholm, Sweden; \\ 2Oral Care AB, Research \& Development \\ Unit, Göteborg, Sweden; ${ }^{3}$ Experimental \\ Dermatology Unit, Department \\ of Neuroscience, Karolinska Institute, \\ Stockholm, Sweden
}

\section{Abstract}

In many countries or regions the capacity of health care resources is below the needs of the population and new approaches for health surveillance are needed. Innovative projects, utilizing wireless communication technology, contribute to reliable methods for field-work data collection and reporting to databases. The objective was to describe a new version of a wireless IT-support system for field-work data collection and administration. The system requirements were drawn from the design objective and translated to system functions. The system architecture was based on fieldwork experiences and administrative requirements. The Smartphone devices were HTC Touch Diamond2s, while the system was based on a platform with Microsoft .NET components, and a SQL Server 2005 with Microsoft Windows Server 2003 operating system. The user interfaces were based on .NET programming, and Microsoft Windows Mobile operating system. A synchronization module enabled download of field data to the database, via a General Packet Radio Services (GPRS) to a Local Area Network (LAN) interface. The field-workers considered the here-described applications user-friendly and almost self-instructing. The office administrators considered that the back-office interface facilitated retrieval of health reports and invoice distribution. The current IT-support system facilitates short lead times from fieldwork data registration to analysis, and is suitable for various applications. The advantages of wireless technology, and paper-free data administration need to be increasingly emphasized in development programs, in order to facilitate reliable and transparent use of limited resources.

\section{Introduction}

The mobile phones and wireless communication systems are increasingly gaining ground, even in many of the world's resourcelimited countries. The rapid development of wireless technology has created new opportunities for reliable field-work data collection, which can be used for resource allocation, and aid distribution in catastrophe areas, or for developing long-standing health care solutions. An example of a technology partnership project is The mHealth Alliance, initiated by the United Nations (UN) and Vodafone Foundations, where mobile technology is used to support UN programs in developing countries. ${ }^{1}$

The global health and development of present days is facing unprecedented problems, as the global financial crisis has threatened the viability of national health care systems. ${ }^{2}$ The health services are today in many regions still inaccessible, or unaffordable, and the global burden of ill-health is increasingly inequitably distributed. ${ }^{2,3}$ In order to be able to respond adequately to emerging global threats with non-communicable diseases, or potential pandemics, health surveillance has never been more important. ${ }^{2}$ For example, considering the Millennium Development Goals (e.g. to 'Improve maternal health') of the UN, ${ }^{4}$ surveillance and improvement of maternal health will affect the whole communities in beneficial ways, starting with the children.

Another increasingly important aspect in the global health arena is that of the non-governmental organizations; special purpose funds and the private sector are becoming significant actors in the global partnership for development. ${ }^{3,5}$ Therefore, to motivate the need of health care support, it is important to have reliable epidemiological data reflecting the true needs of the population. Subsequently, it is also important to be able to measure the gains achieved through the support given with full transparency. ${ }^{6}$ To achieve this, in areas with relatively few health care professionals per capita, ${ }^{7,8}$ the equipment for field data registration, as well as the technology for data storage, needs to be flexible and easily adaptable to enable its use for both general health registrations, as well as for more detailed ones in the same system. ${ }^{9}$

The intensive development of telecom networks and mobile phone-based services in the emerging markets have led to the launch of new services that offer agricultural, market and health information via mobile phones. ${ }^{10}$ Even in remote areas, these phone- or computer-based services lead people to nearby clinics, and send text messages to explain symptoms of common diseases. ${ }^{10,11}$ Thus, in the global health context, a new era of telecom medical services is arising, and personal digital assistants (PDAs), or handheld computers, have found widespread use in various applications in health care settings. ${ }^{12,13}$ These systems are
Correspondence: Petteri Sjögren, Oral Care AB, Research \& Development Unit, Drottninggatan 13, SE-411 14, Göteborg, Sweden.

Tel. +46.735.158003 - Fax: +46.31.138515.

E-mail: petteri.sjogren@oralcare.se

Key words: developing countries, global health, handheld computers, information storage and retrieval methods, international organizations.

Acknowledgements: 0J was supported by grants from the Karolinska Institute, the Cancer and Allergy Foundation (Cancer- och Allergifonden), and the Help Foundation (Hjälpfonden).

Received for publication: 13 September 2010. Accepted for publication: 6 Decembe 2010 .

This work is licensed under a Creative Commons Attribution 3.0 License (by-nc 3.0).

(C) Copyright M. Forsell et al., 2011

Licensee PAGEPress, Italy

Journal of Public Health in Africa 2011; 2:e3

doi:10.4081/jphia.2011.e3

also increasingly compatible to already available mobile network systems almost all over the world. ${ }^{9}$ Thus, these wireless systems allow patient data collection and information retrieval under field-work conditions, or in hospital wards. In addition, computerized, or phone-based, data collection improves confidentiality and reliability, in comparison to handwritten registration methods (i.e. paperand-pencil) for health surveillance. ${ }^{13}$

Available wireless systems are suitable for field-work environments almost everywhere, where some infrastructure or technology is available. ${ }^{10}$ A major design objective for fieldwork applications should be to create an easyto-use interface, which has been shown to be a key factor for successful portable IT-support systems. ${ }^{9}$ It is also important that the system requirements facilitate data administration, before and after the field data registrations, for planning or research purposes. ${ }^{9}$ Therefore, this study was initiated with the aim to describe the development of a wireless IT-support system for field-work data collection and administration.

\section{Material and Methods}

The system design, construction, and implementation of the first version of the PDA application (MobilDent) for an IT-support system for field-work data collection was described in detail in a previous report. ${ }^{9}$ Briefly, the design objective behind MobilDent system was to develop and implement a mobile PDA system 
that would facilitate field-work and the administrative handling of data before and after the field-work registrations. The system requirements for MobilDent (Oral Care AB, Stockholm, Sweden) were collected, using a modified Question Option Criteria (QOC) design rationale. ${ }^{14}$ The system requirements drawn from the design objective were analyzed and translated to system functions, whereas the outlined system architecture was based on field-work experiences and administrative requirements for a back-office system. ${ }^{9}$ MobilDent was based on a platform with .NET (Microsoft Corp., Redmond, WA, USA) components, using a Microsoft SQL Server 2005 for data storage, with the Windows Server 2003 operating system. The MobilDent server application was made responsible for retrieving data from field data repository, data translation and formatting for database storage and administrative purposes. For secure data storage the MobilDent database runs on a SQL server with redundant drives in a secure server hotel. A full database backup is done daily and the tape is stored at a separate physical location. To further develop the system the older PDAs were exchanged to Smartphone devices, and the back-office user interface was modernized. In addition, a wireless synchronization system was developed to facilitate download of field data.

\section{Results}

The PDAs in the upgraded MobilDent 2.2 application were exchanged to Smartphone devices, HTC Touch Diamond2s (HTC Europe Co. Ltd., Slough, UK). The system was based on a platform with Microsoft .NET components, using a Microsoft SQL Server 2005 for data storage, with the Windows Server 2003 operating system. ${ }^{9}$ The user interfaces were based on .NET programming, and a Microsoft Windows Mobile operating system, with user-friendly data entry screens suitable for efficient data collection and field-work administration on a Smartphone display (Figure 1).

As previously, the back-office and the database system were utilized for patient data administration and data storage, and the MobilDent 2.2 back-office interface was designed to enable administration and database handling on different displays suitable for administration on a normal-sized computer screen (Figure 2). ${ }^{9}$ However, in the upgraded MobilDent 2.2 system a synchronization module was connected via a General Packet Radio Services (GPRS) to a Local Area Network (LAN) interface to enable download of field data from the Smartphone devices to the backoffice and the database systems.

The original MobilDent system has been used since January 2006 for oral health data collection in outreach dentistry field-work in Sweden. ${ }^{9}$ The registrations in the current application were related to different aspects of oral health, but may easily be modified to bespoke data collection purposes.

\section{Discussion}

The MobilDent system was further developed as a response to a demand for an efficient administration in a growing field-work organization. For health care of elderly, as well as for other field-work conditions, mobile systems are very suitable since it may be difficult for the patients to access professional health care facilities. During the system design it was considered important that the field-workers would be able to collect the required patient data conveniently. In addition, it was important that the administration before and after the field-work would be rationalized with a high level of data security. Therefore, a major design objective was to create an easy-to-use interface, previously characterized to be the most successful factor for mobile care systems. ${ }^{15}$ Thus, the chosen system architecture was a trade-off between the requirements of a state-of-the-art data collection system and a pragmatic tool for the field-workers. ${ }^{16}$ Experiences gained from field-work with the new MobilDent 2.2 system revealed that the MobilDent Smartphone devices were considered feasible, user-friendly and almost self-instructing. Among the office administrators the general impression was that MobilDent 2.2 back-office system had an easy-to-navigate interface, which facilitated retrieval of health reports and invoices for purchasers. The MobilDent database is now growing by $>40,000$ oral health records per year, and is considered a valuable data source for care planning, educational purposes, epidemiological research, and resource allocation

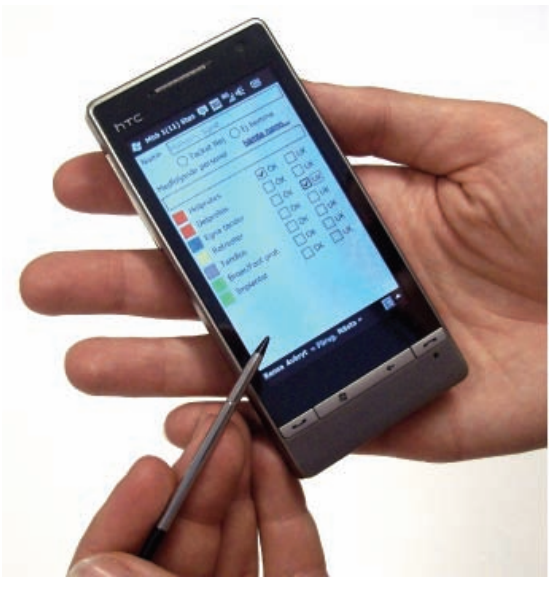

Figure 1. A smartphone for field-work data collection.
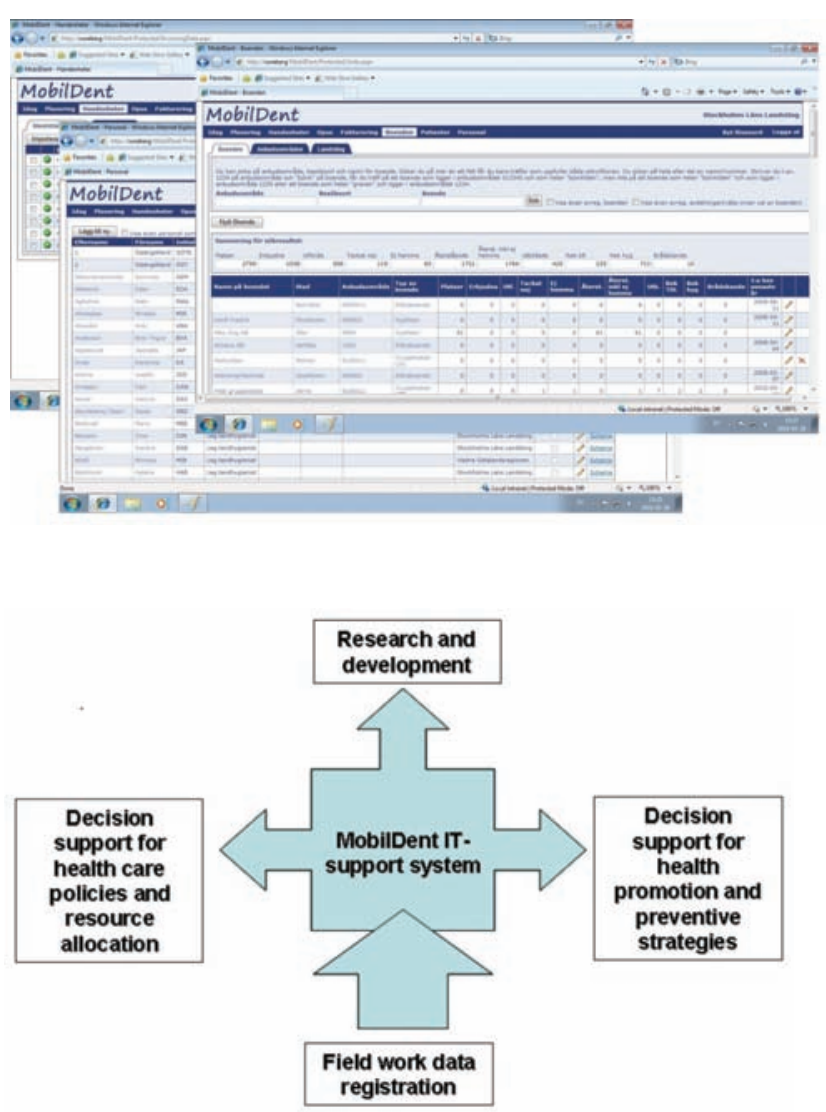

Figure 2. The MobilDent 2.2 back-office interface, suitable for a normal-sized computer screen. The back-office interface enables the administrative staff to conveniently access, for example, selected field-work data, field-work schedules, fieldwork site addresses, invoices, and statistical summaries.

Figure 3. Schematic illustration of the potential of an ITsupport system in field-work data collection. 
(Figure 3). In addition, the collected data may be used for prognostic purposes when the need of care, or health promotion, within a certain geographical area is planned in the future. The MobilDent 2.2 back-office administration system has also further rationalized the administration by eliminating a vast amount of paper sheets that previously had to be hand-written and stored. Furthermore, the time span between the health assessments and the actual care provided has diminished, and the risk of missing patients in need of care has been virtually eliminated.

Available wireless systems are suitable for field-work environments almost anywhere in the world where, at least, some infrastructure and technology is available. ${ }^{10}$ These modern data collection systems are small, relatively cheap, and almost self-instructing. Therefore, a mobile data collection system often pays back its investment costs relatively quickly. ${ }^{10}$ Not even a complete IT-support system needs to require considerable investments, since standard components may be used to construct the system, and open source operating systems are readily available. ${ }^{11}$ The wireless data collection systems may be designed to be adaptable for bespoke user applications, with relatively little re-programming. This is very useful for fieldwork organizations, since the surveys need to be changed or modified on a regularly basis. Wireless synchronization to databases also diminishes the lead time between data collection and decision-making, and also increases the reliability of data by elimination sources of discrepancies in the administrative processes. The handheld devices may also run in parallel with Global Positioning Systems, and the collected data may be displayed in the back-office system interface with a Geographic Information System. ${ }^{17}$ Importantly, a mobile field-work data collection system needs to be able to instantly transmit the collected data to a central database, where the collected information can be analyzed and used for rapid resource allocation within a certain geographical area, or for prognostic purposes. On-demand or realtime wireless synchronization to a back-office system is especially important in catastrophe areas. However, in any context, it will rationalize the administration routines by eliminating a vast amount of, previously hand-written, paper sheets. ${ }^{9,13}$ Thus, instead of administration, the field-work staff may rather focus on the data collection procedures as well as the remedies to-follow.

\section{Conclusions}

Mobile PDA- or phone-based systems present excellent opportunities for field-work data collection. The current IT-support system facilitates short lead times from field-work data registration to analysis, and is suitable for various field-work applications. The advantages of wireless technology, and paper-free data administration need to be increasingly emphasized in development programs, in order to facilitate reliable and transparent use of limited resources.

\section{References}

1. United Nations Foundation. mHealth Alliance project 2010. Available at: http://www.unfoundation.org/globalissues/technology/mhealth-alliance.html

2. World Health Organisation. 7th Global Conference on Health Promotion, 2009. Available at: http://www.who.int/healthpromotion/conferences/7gchp/en/

3. United Nations. The Millenium Development Goals Report 2008. Available at: http://www.un.org/millenniumgoals/ pdf/The\%20Millennium\%20Development $\%$ 20Goals\%20Report\%202008.pdf

4. Ooms G, Stuckler D, Basu S, McKee M. Financing the Millennium Development Goals for health and beyond: sustaining the 'Big Push'. Global Health 2010;6:17.

5. Howard LM. Public and private donor financing for health in developing countries. Infect Dis Clin North Am 1991;5:22134.

6. Diap G, Amuasi J, Boakye I, et al. Antimalarial market and policy surveys in subSaharan Africa. Malar J 2010;9:S1.

7. Anyangwe SC, Mtonga C. Inequities in the global health workforce: the greatest impediment to health in sub-Saharan Africa. Int J Environ Res Public Health 2007;4:93-100.

8. Naicker S, Plange-Rhule J, Tutt RC, Eastwood JB. Shortage of healthcare workers in developing countries--Africa. Ethn Dis 2009;19:S1-60-4.

9. Forsell M, Häggström M, Johansson 0, Sjögren P. A personal digital assistant application (MobilDent) for dental fieldwork data collection, information management and database handling. Br Dent $\mathrm{J}$ 2008;205:E17.

10. The Economist. A special report on telecoms in emerging markets. Available at: http://www.economist.com/node/14483896

11. Anantraman V, Mikkelsen T, Khilnani R, et al. Open source handheld-based EMR for paramedics working in rural areas. Proc AMIA Symp 2002:12-6.

12. Bobula JA, Anderson LS, Riesch SK, et al. Enhancing survey data collection among youth and adults: use of handheld and laptop computers. Comput Inform Nurs 2004;22:255-65.

13. Yu P, de Courten M, Pan E, et al. The development and evaluation of a PDA-based method for public health surveillance data collection in developing countries. Int $\mathrm{J}$ Med Inform 2009;78:532-42.

14. Sjöberg C. Voices in design: argumentation in participatory development. Thesis No. 436, 1994. University of Linköping, Sweden.

15. El-Solh AA, Pietrantoni C, Bhat A, et al. Colonization of dental plaques a reservoir of respiratory pathogens for hospital acquired pneumonia in institutionalized elders. Chest 2004;126:1575-82.

16. Scannapieco FA, Bush RB, Paju S. Associations between periodontal disease and risk for nosocomial bacterial pneumonia and chronic obstructive pulmonary disease. A systematic review. Ann Periodontol 2003;8:54-69.

17. Khan OA, Davenhall W, Ali M, et al. Geographical information systems and tropical medicine. Ann Trop Med Parasitol 2010;104:303-18. 